\title{
Time dependent ethnic convergence in colorectal cancer survival in
} hawaii

\author{
Ian S Pagano*1, Shane Y Morita ${ }^{2}$, Sanjaya Dhakal ${ }^{1}$, Scott A Hundahl ${ }^{3}$ and \\ Gertraud Maskarinec ${ }^{1}$
}

\begin{abstract}
Address: ${ }^{1}$ Cancer Research Center of Hawai'i, University of Hawai'i, Lauhala Street, Honolulu, HI, ${ }^{2}$ Department of Surgery, University of Hawai'i, Honolulu, HI and ${ }^{3}$ VA Northern California Health Care System, Hospital Way, Mather, CA

Email: Ian S Pagano* - ian@crch.hawaii.edu; Shane Y Morita - smorita1@socal.rr.com; Sanjaya Dhakal - everest-sanju@hotmail.com; Scott A Hundahl - shundahl@queens.org; Gertraud Maskarinec - gertraud@crch.hawaii.edu

* Corresponding author
\end{abstract}

Published: 25 February 2003

BMC Cancer 2003, 3:5

This article is available from: http://www.biomedcentral.com//47/-2407/3/5

(C) 2003 Pagano et al; licensee BioMed Central Ltd. This is an Open Access article: verbatim copying and redistribution of this article are permitted in all media for any purpose, provided this notice is preserved along with the article's original URL.

\begin{abstract}
Background: Although colorectal cancer death rates have been declining, this trend is not consistent across all ethnic groups. Biological, environmental, behavioral and socioeconomic explanations exist, but the reason for this discrepancy remains inconclusive. We examined the hypothesis that improved cancer screening across all ethnic groups will reduce ethnic differences in colorectal cancer survival.
\end{abstract}

Methods: Through the Hawaii Tumor Registry 16,424 patients diagnosed with colorectal cancer were identified during the years 1960-2000. Cox regression analyses were performed for each of three cohorts stratified by ethnicity (Caucasian, Japanese, Hawaiian, Filipino, and Chinese). The models included stage of diagnosis, year of diagnosis, age, and sex as predictors of survival.

Results: Mortality rates improved significantly for all ethnic groups. Moreover, with the exception of Hawaiians, rates for all ethnic groups converged over time. Persistently lower survival for Hawaiians appeared linked with more cancer treatment.

Conclusion: Ethnic disparities in colorectal cancer mortality rates appear primarily the result of differential utilization of health care. If modern screening procedures can be provided equally to all ethnic groups, ethnic outcome differences can be virtually eliminated.

\section{Background}

After lung, prostate, and breast cancer, colorectal cancer ranks as a leading source of cancer mortality.[1] Nationally, although death rates have been declining since the mid-1980s, this trend is not consistent across all ethnic groups.[2] Specifically, in the past 10 years the death rate for Caucasians has been decreasing at nearly twice the rate as that for African Americans, and for Native Americans the rate has actually been increasing. [3,4] Among Asian ethnic groups, Chinese and Filipinos suffer a higher death rate than do the Japanese.[5] These ethnic disparities appear largely driven by differential stage distribution (e.g., more advanced stage cases at presentation). Underutilization of cancer screening appears a key factor.[6] However, studies have found that even after controlling for stage at diagnosis, significant ethnic differences remain.[7]

How can one explain cancer survival differences that persist after adjustment for stage? Biological theories suggest that members of certain ethnic groups are genetically 
predisposed to more aggressive forms of the disease, differ in host-tumor interactions, or are more likely to have contributing comorbid conditions. Wudel et al. (2002) recently reported that colorectal cancer survival differences between Caucasians and African Americans could not be explained by measurable differences in treatment.[8] Neuhausen has proposed a multi-factorial biology-utilization model.[9] Environmental theories propose that behavioral or socioeconomic factors leading to differential utilization of medical care are responsible. Varying utilization of, as well as access to health care has been reported as an explanation. [10-12] Schrijvers et al. (1997) have described a relation between socioeconomic status and comorbidity.[13] Evidence of interaction between age and socioeconomic status has also been reported.[14]

Hawaii's diverse ethnic composition combined with its long-standing statewide cancer registry, the Hawaii Tumor Registry (HTR), offer an ideal setting for examining ethnic differences in cancer survival. Previous research has documented significant survival disparities among the major ethnic groups (Caucasian, Japanese, Hawaiian, Filipino, and Chinese) in the state. In 1978, Nomura et al. found that Japanese patients had a nearly one-third higher survival rate than Caucasians. [15] Hirohata et al. (1977) described better survival rates among Japanese and Caucasians than among Filipinos and Hawaiians, even after adjusting for age, gender, and extent of disease at diagnosis.[16] Wegner et al. (1982) analyzed HTR data from 1960-1974 and found the same pattern of differences, which also could not be explained by any of the available covariates.[17]

The goal of the present study is to examine trends in recent survival rates. The HTR data that was incorporated in the Wegner (1982) study is still available as is more recent data up to the year 2000, allowing for an examination of survival patterns over time. Improved survival rates for cancer patients were observed by Hinds et al. (1983) during the years 1960-1974.[18] More recently, Maskarinec et al. (1999) have described improved breast cancer survival among all ethnic groups for 1970-1990.[19] Also, for the years 1995-1998 it was found that all ethnic disparities in breast cancer survival were eliminated once TNM Stage had been controlled.[20] These findings largely fail to support purely biologic explanations of disparate colorectal cancer survival. Differential utilization of health care or access to health care appears more important.

In Hawaii, the passage of time has brought general improvements in medical care and also narrowed disparities in access to medical care. Utilization of screening procedures continues to vary among ethnic groups, however. At the onset of this study, we hypothesized that, over the past
30 years, improved cancer screening and treatment, as well as better access to medical care across all ethnic groups has both improved survival rates and reduced ethnic differences in colorectal cancer survival. We further predicted that stage at diagnosis, age, and gender could explain most remaining survival differences, although we questioned the role of other factors such as treatment utilization and co-morbid disease.

\section{Methods \\ Population and Sample}

The population of Hawaii resides on seven islands with $80 \%$ on the island of Oahu and is estimated at 1.2 million with approximately 580,000 women. [21] Close to $13 \%$ of residents are 65 years and older and $40 \%$ are 40 years and older. The majority of the population is of Asian and Pacific Islander descent: $24.1 \%$ of the population in 1990 were Caucasian, $20.4 \%$ Japanese, $18.8 \%$ Native Hawaiian, $11.4 \%$ Filipino, $4.7 \%$ Chinese, and the rest other ethnic groups. However, over the period of this study, differences in age distribution within various ethnic groups in Hawaii have driven some differences in the actual proportions of individuals with cancer.

All data were ascertained through the Hawaii Tumor Registry (HTR), which provides population-based coverage of all newly diagnosed cancer cases and subsequent followup status for residents of Hawaii. The HTR was established in 1960 and it became part of the Surveillance, Epidemiology, and End Results (SEER) program in 1973. Quality control reviews have shown that case-ascertainment through HTR is virtually complete. Over $99 \%$ of cancer cases reported to the registry are histologically confirmed[22] and less than $2 \%$ of cases are identified through death certificates only. Whenever possible, the HTR follows cases until death through regular linkages with the Hawaii Department of Health's death records, hospital-based registries, and additional sources of mortality information. In accordance with SEER rules, less than $5 \%$ of cases are lost to follow-up. The ethnicity classification in the HTR is based on self-reports by patients. Information on the first course of treatment (surgery, chemotherapy, radiation, and hormone therapy) is also collected.[23]

From the HTR, all patients diagnosed with colorectal cancer (ICD-O-2 codes: C18.0-C18.9, C19.9, C20.9, C21.0C21.2, C21.8) from 1960-2000 were extracted. Of the 17,416 pathologically confirmed cases of invasive colorectal cancer, we excluded 757 patients who were not from the five major ethnic groups (Caucasian, Japanese, Hawaiian, Filipino, and Chinese) and 235 patients for whom the diagnosis date was unknown, leaving a total sample of 16,424 cases for analysis. 


\section{Statistical Analyses}

Data were first examined for ethnic differences by cohort across stage at diagnosis, age, sex, and cause of death using the likelihood ratio $\chi^{2}$ statistic. This statistic is interpreted in the same manner as the Pearson $\chi^{2}$, but provides greater precision. Next, the SAS procedure PHREG,[24] which performs regression analyses based on the Cox proportional hazards model, was used to conduct survival analyses. As a test of the validity of the proportional hazards assumption (that the hazard ratio does not change over time), the Cox proportional hazards regression was performed with a variable calculated as the mean deviated natural log of time. Significance of this variable would imply a violation of the proportional hazards assumption. Survival (survivor function) estimates (used for figures) were based on the fitted proportional hazards model, and can be interpreted as the estimates for the survivor functions controlling for the effects of the covariates.[25] The same analyses were conducted in each of three separate cohorts determined by the year of diagnosis: 1960-1974, 1975-1987, and 1988-2000. The years for the first cohort were chosen to be consistent with the study conducted by Wegner et al.[17]

The starting year for the third cohort was chosen as 1988 because that was the first year in which TNM staging data (tumor size, node status, and metastases) became available in the HTR.[26] With TNM stage data, a comparison between the predictive value of this more comprehensive form of staging (0, I, IIA, IIB, IIIA, IIIB, and IV) and the SEER staging (local, regional, distant) could be made.[26] The was accomplished by computing the increment in model fit after the TNM stage variable had been added to model containing the SEER stage variable. The likelihood ratio statistic provides this information and is distributed as chi-square, allowing for determination of statistical significance. The years for the second cohort consisted simply of the years between cohorts one and three.

Within each cohort two sets of survival analyses were performed: In the first, an event was considered to have occurred if a patient died as a result of colorectal cancer; in the second, death by any other cause was considered an event. This allowed for an assessment of whether or not changing colorectal cancer survival trends were consistent with general survival trends. Censored values included patients alive at the last data collection and patients lost to follow-up. In all analyses the effect of ethnicity on survival, while controlling for the variables stage at diagnosis (local, regional, distant), age, sex, and year of diagnosis (to control for any linear time trends existing within cohorts), was assessed using a hierarchical approach in which a model including ethnicity was compared to one that did not. Age and year of diagnosis were treated as con- tinuous variables, as examinations did not reveal any nonlinear associations.

\section{Results}

Tables 1 and 2 provide frequency and percentage distribution data for stage at diagnosis, age, sex, and cause of death by ethnicity and cohort. The average ages for each stage at diagnosis were 66.6 years for local, 65.9 years for regional, and 65.5 years for distant. For each variable, significant ethnic differences were observed. When compared to the other ethnic groups, Hawaiians in all three cohorts were diagnosed at a more advanced stage [Likelihood Ratio $\chi^{2}(8)=36.8,25.0$, and 46.0; $p<.0001, p<$ .01 , and $p<.0001$ respectively] and were more likely to have died from colorectal cancer (as opposed to death by other causes or still alive) [Likelihood Ratio $\chi^{2}(8)=36.5$, 71.2, and 69.6; $\mathrm{p}<.0001$ for all]. Hawaiians also were significantly younger within cohorts 2 and 3 [Likelihood Ratio $\chi^{2}(4)=92.3$ and $180.5 ; p<.0001$ for both]. When compared to the other ethnic groups, Filipinos had a significantly higher proportion of males in all three cohorts [Likelihood Ratio $\chi^{2}(4)=140.1,92.7$, and 32.1; $p<.0001$ for all].

Figure 1 presents the survivor function plots (stratified by ethnicity) for each cohort and for each cause of death category (controlled for stage at diagnosis, year of diagnosis, age, and sex). The corresponding five-year survivor estimates with 95\% confidence intervals are shown in Table 3 , and the parameter estimates for each Cox regression model are provided in Table 4. Unadjusted five-year survival rates for each ethnic group were $80.5 \%$ for Japanese, $79.4 \%$ for Caucasian, $78.8 \%$ for Chinese, $76.4 \%$ for Filipino, and $72.5 \%$ for Hawaiian. The test of the validity of the proportional hazards assumption with the variable $\left[\log _{e}(\right.$ time $\left.)-0.52\right]$ indicated no violation $\left[\chi^{2}(1)=0.13, p=\right.$ $0.72]$.

When an event was considered death by colorectal cancer, significant ethnic differences were found for all three cohorts [Likelihood Ratio $\chi^{2}(4)=20.0,23.1$, and 12.0; $p<$ $.001, p<.001$, and $p<.05$ respectively]. An examination of the confidence intervals for cohort 1 indicated that Japanese and Caucasian patients had significantly longer five-year survival than Filipino and Hawaiian patients. For the second cohort, the confidence intervals indicated that Caucasians had a significantly longer survival time than Filipinos; and in the third cohort, Hawaiians had significantly shorter survival time than all other ethnic groups. When an event was considered any death not caused by colorectal cancer, significant ethnic differences were again found for all three cohorts [Likelihood Ratio $\chi^{2}(4)=46.3$, 73.3 , and 57.9; $p<.0001$ for all]. Confidence intervals indicated that the Japanese always had a significantly higher survival rate than at least one other ethnic group. 
Table I: Frequency of Colorectal Cancer Cases Diagnosed in Hawaii from 1960-2000.

\begin{tabular}{|c|c|c|c|c|c|c|c|c|c|c|c|c|c|c|c|c|c|c|}
\hline \multirow{2}{*}{$\begin{array}{l}\text { ETHNICITY } \\
\text { COHORT }\end{array}$} & \multicolumn{3}{|c|}{ Caucasian } & \multicolumn{3}{|c|}{ Japanese } & \multicolumn{3}{|c|}{ Hawaiian } & \multicolumn{3}{|c|}{ Filipino } & \multicolumn{3}{|c|}{ Chinese } & \multicolumn{3}{|c|}{ TOTAL } \\
\hline & 1 & 2 & 3 & I & 2 & 3 & 1 & 2 & 3 & 1 & 2 & 3 & 1 & 2 & 3 & 1 & 2 & 3 \\
\hline \multicolumn{19}{|l|}{ STAGE } \\
\hline local & 318 & 588 & 994 & 403 & 901 & 1668 & 59 & 178 & 299 & 90 & 246 & 440 & 79 & $|7|$ & 299 & 949 & 2084 & 3700 \\
\hline regional & 338 & 671 & 712 & 500 & 945 & 1210 & 57 & 143 & 279 & 116 & 236 & 334 & 97 & 167 & 191 & 1108 & 2162 & 2726 \\
\hline distant & 240 & 324 & 360 & 208 & 390 & 453 & 58 & 102 & 153 & 83 & 139 & 146 & 59 & 86 & 69 & 648 & 1041 & 1181 \\
\hline missing & 78 & 122 & 168 & 62 & 68 & 106 & 11 & 14 & 37 & 12 & 34 & 60 & 11 & 20 & 22 & 174 & 258 & 393 \\
\hline \multicolumn{19}{|l|}{ AGE } \\
\hline$<65$ & 545 & 649 & 804 & 600 & 1033 & 1026 & 107 & 256 & 417 & 153 & 227 & 359 & $12 \mid$ & 153 & 154 & 1526 & 2318 & 2760 \\
\hline$\geq 65$ & 429 & 1056 & 1430 & 573 & $|27|$ & 2411 & 78 & 181 & 351 & 148 & 428 & 621 & 125 & 291 & 427 & 1353 & 3227 & 5240 \\
\hline \multicolumn{19}{|l|}{ SEX } \\
\hline male & 488 & 935 & 1299 & 669 & 1392 & 1985 & 99 & 266 & 427 & 259 & 495 & 637 & 153 & 248 & 299 & 1668 & 3336 & 4647 \\
\hline female & 486 & 770 & 935 & 504 & 912 & 1452 & 86 & 171 & 341 & 42 & 160 & 343 & 93 & 196 & 282 & 1211 & 2209 & 3353 \\
\hline \multicolumn{19}{|l|}{ DEATH } \\
\hline cr cancer & 331 & 567 & 506 & 422 & 859 & 775 & 93 & 182 & 246 & 142 & 251 & 234 & 99 & 161 & 124 & 1087 & 2020 & 1885 \\
\hline other & 537 & 810 & 636 & 607 & 839 & 764 & 82 & 167 & 156 & 129 & 284 & 248 & 122 & 196 & 127 & 1477 & 2296 & 1931 \\
\hline censored & 106 & 328 & 1092 & 144 & 606 & 1898 & 10 & 88 & 366 & 30 & 120 & 498 & 25 & 87 & 330 & 315 & 1229 & 4184 \\
\hline TOTAL & 974 & 1705 & 2234 & 1173 & 2304 & 3437 & 185 & 437 & 768 & 301 & 655 & 980 & 246 & 444 & 581 & 2879 & 5545 & 8000 \\
\hline
\end{tabular}

Notes. Cohort relates years of diagnosis, where cohort I is 1960-1974, cohort 2 is 1975-1987, and cohort 3 is I988-2000. Death relates cause of death information, where cr cancer indicates colorectal cancer, other indicates any other cause, and censored indicates alive or missing. Stage is SEER staging.

Results were largely consistent with our hypothesis, but with one major exception: the persistently low Hawaiian colorectal cancer survival in cohort 3 . This unpredicted finding led to post hoc analyses that were identical to the previous Cox regression models, but included the available treatment variables (surgery, chemotherapy, radiation, and hormone therapy) as additional predictors. Table 5 provides the percentages of each ethnic group receiving a given treatment by stage. With the inclusion of treatment variables, ethnic differences were no longer significant in the third cohort, but remained significant in the first two [Likelihood Ratio $\chi^{2}(4)=25.3,29.1$, and 8.2; $p<.0001$, $p<.0001$, and $p=.08$ respectively]. See Figure 2 .

Additionally, we tested the post hoc hypothesis that Hawaiians have lower survival because they were both younger and diagnosed at a more advanced stage than the other groups. If advanced disease is more aggressive in young people, this could explain why the Hawaiians had lower survival. An interaction term between age and stage at diagnosis was created and added to the models run previously. However this interaction term did not show statistical significance, failing to support the post hoc hypothesis.

At least for cohort 3, our data also allowed us to compare the predictive value of the SEER staging variable (local, re- gion, and distant) with that of the more comprehensive TNM staging variable. TNM staging provided significantly improved predictive value over SEER staging [Likelihood Ratio $\left.\chi^{2}(1)=126.4 ; p<.0001\right]$. However, inclusion of TNM staging did not eliminate the Hawaiian ethnic disparity in outcome [Likelihood Ratio $\chi^{2}(4)=11.7, p<$ $.05]$, again suggesting that stage at diagnosis alone does not account for the persistently low survival among Hawaiians.

\section{Discussion}

With few exceptions, results clearly supported the stated hypothesis that ethnic disparities in colorectal cancer survival have been diminishing over time. Figure 1, showing the convergence of survival over time, best exemplifies this. The one discrepancy in this overall trend is the unchanged life expectancy for the Hawaiian group in cohort 3. A comparison with the survival curves for other causes of death within cohort 3 reveals that this effect is specific to colorectal cancer and does not reflect a general tendency for Hawaiians to die sooner.

One possible explanation for this is that Hawaiians were not utilizing medical care to treat colorectal cancer to the same degree as other ethnic groups. Our post hoc analyses did demonstrate that ethnic disparities were no longer statistically significant after controlling for treatment differ- 


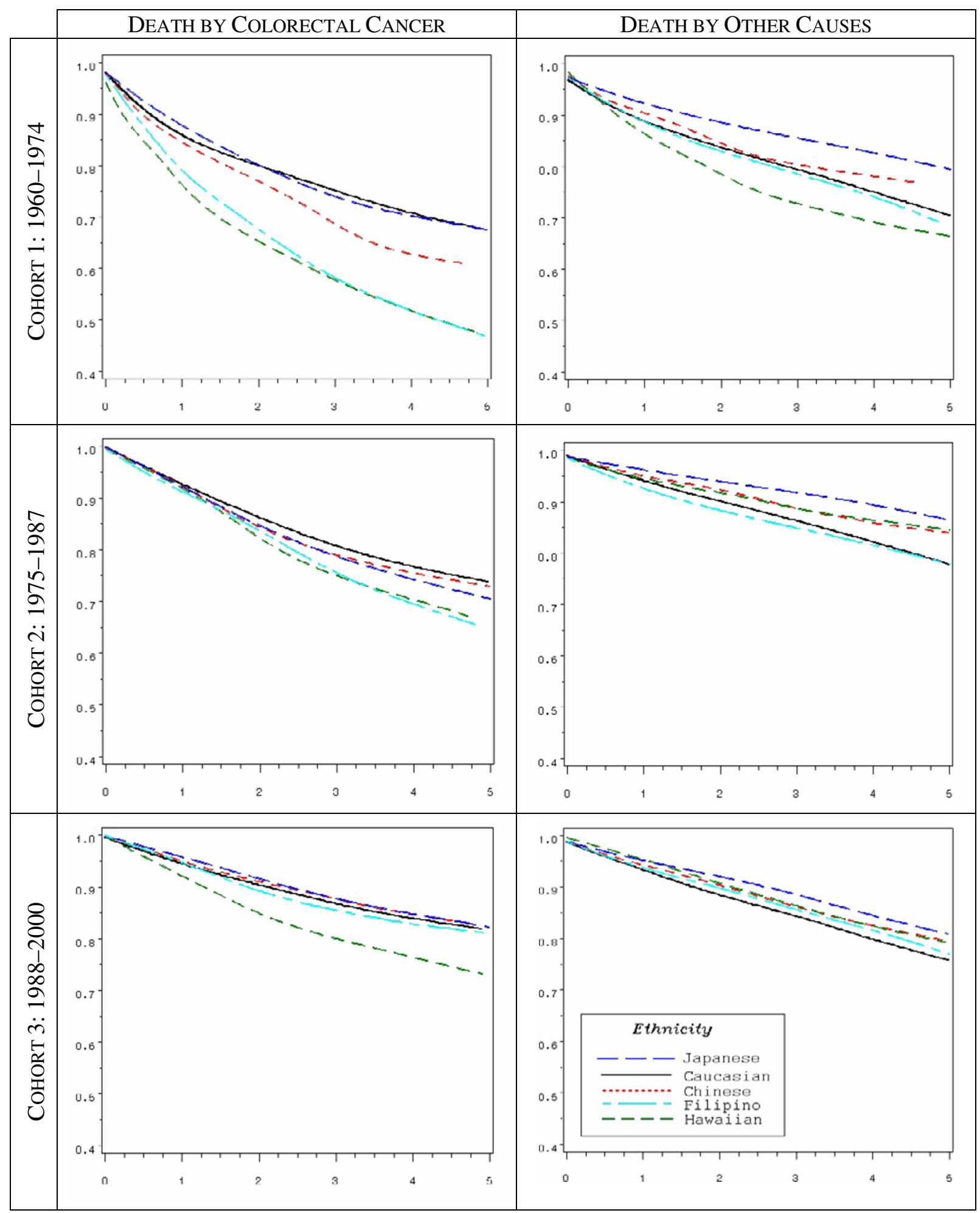

\section{Figure I}

Estimated Survival versus Time (Years) by Ethnicity. Estimated survival (survivor functions) versus time (years) stratified by ethnicity for each cohort (1960-1974, 1975-1987, and 1988-2000) and cause of death category, controlling for the effects of SEER stage at diagnosis, year of diagnosis, age, and sex are provided. 
Table 2: Percentages of Colorectal Cancer Cases Diagnosed in Hawaii from 1960-2000.

\begin{tabular}{|c|c|c|c|c|c|c|c|c|c|c|c|c|c|c|c|c|c|c|}
\hline \multirow{2}{*}{$\begin{array}{l}\text { ETHNICITY } \\
\text { COHORT }\end{array}$} & \multicolumn{3}{|c|}{ Caucasian } & \multicolumn{3}{|c|}{ Japanese } & \multicolumn{3}{|c|}{ Hawaiian } & \multicolumn{3}{|c|}{ Filipino } & \multicolumn{3}{|c|}{ Chinese } & \multicolumn{3}{|c|}{ TOTAL } \\
\hline & 1 & 2 & 3 & 1 & 2 & 3 & 1 & 2 & 3 & I & 2 & 3 & 1 & 2 & 3 & I & 2 & 3 \\
\hline \multicolumn{19}{|l|}{ STAGE } \\
\hline local & 32.6 & 34.5 & 44.5 & 34.4 & 39.1 & 48.5 & 31.9 & 40.7 & 38.9 & 29.9 & 37.6 & 44.9 & 32.1 & 38.5 & 51.5 & 33.0 & 37.6 & 46.3 \\
\hline regional & 34.7 & 39.4 & 31.9 & 42.6 & 41.0 & 35.2 & 30.8 & 32.7 & 36.3 & 38.5 & 36.0 & 34.1 & 39.4 & 37.6 & 32.9 & 38.5 & 39.0 & 34.1 \\
\hline distant & 24.6 & 19.0 & 16.1 & 17.7 & 16.9 & 13.2 & 31.4 & 23.3 & 19.9 & 27.6 & 21.2 & 14.9 & 24.0 & 19.4 & 11.9 & 22.5 & 18.8 & 14.8 \\
\hline missing & 8.0 & 7.2 & 7.5 & 5.3 & 3.0 & 3.1 & 5.9 & 3.2 & 4.8 & 4.0 & 5.2 & 6.1 & 4.5 & 4.5 & 3.8 & 6.0 & 4.7 & 4.9 \\
\hline \multicolumn{19}{|l|}{ AGE } \\
\hline$<65$ & 56.0 & 38.1 & 36.0 & 51.2 & 44.8 & 29.9 & 57.8 & 58.6 & 54.3 & 50.8 & 34.7 & 36.6 & 49.2 & 34.5 & 26.5 & 53.0 & 41.8 & 34.5 \\
\hline$\geq 65$ & 44.0 & 61.9 & 64.0 & 48.8 & 55.2 & 70.1 & 42.2 & 41.4 & 45.7 & 49.2 & 65.3 & 63.4 & 50.8 & 65.5 & 73.5 & 47.0 & 58.2 & 65.5 \\
\hline \multicolumn{19}{|l|}{ SEX } \\
\hline male & 50.1 & 54.8 & 58.1 & 57.0 & 60.4 & 57.8 & 53.5 & 60.9 & 55.6 & 86.0 & 75.6 & 65.0 & 62.2 & 55.9 & 51.5 & 57.9 & 60.2 & 58.1 \\
\hline female & 49.9 & 45.2 & 41.9 & 43.0 & 39.6 & 42.2 & 46.5 & 39.1 & 44.4 & 14.0 & 24.4 & 35.0 & 37.8 & 44.1 & 48.5 & 42.1 & 39.8 & 41.9 \\
\hline \multicolumn{19}{|l|}{ DEATH } \\
\hline cr cancer & 34.0 & 33.3 & 22.6 & 36.0 & 37.3 & 22.5 & 50.3 & 41.6 & 32.0 & 47.2 & 38.3 & 23.9 & 40.2 & 36.3 & 21.3 & 37.8 & 36.4 & 23.6 \\
\hline other & 55.1 & 47.5 & 28.5 & 51.7 & 36.4 & 22.2 & 44.3 & 38.2 & 20.3 & 42.9 & 43.4 & 25.3 & 49.6 & 44.1 & 21.9 & 51.3 & 41.4 & 24.1 \\
\hline censored & 10.9 & 19.2 & 48.9 & 12.3 & 26.3 & 55.2 & 5.4 & 20.1 & 47.7 & 10.0 & 18.3 & 50.8 & 10.2 & 19.6 & 56.8 & 10.9 & 22.2 & 52.3 \\
\hline TOTAL & 100 & 100 & 100 & 100 & 100 & 100 & 100 & 100 & 100 & 100 & 100 & 100 & 100 & 100 & 100 & 100 & 100 & 100 \\
\hline
\end{tabular}

Notes. Cohort relates years of diagnosis, where cohort I is 1960-1974, cohort 2 is 1975-1987, and cohort 3 is 1988-2000. Death relates cause of death information, where cr cancer indicates colorectal cancer, other indicates any other cause, and censored indicates alive or missing. Stage is SEER staging.

Table 3: Probabilities of Surviving Five Years Among Three Cohorts of Colorectal Cancer Patients

\begin{tabular}{|c|c|c|c|}
\hline \multirow[t]{2}{*}{ COHORT } & \multirow[t]{2}{*}{ ETHNICITY } & \multicolumn{2}{|c|}{ CAUSE OF DEATH } \\
\hline & & Colorectal Cancer & Other \\
\hline \multirow[t]{5}{*}{ I 1960-1974 } & Japanese & $.68(.65-.7 I)$ & $.79(.77-.82)$ \\
\hline & Caucasian & $.68(.64-.7 I)$ & $.71(.67-.74)$ \\
\hline & Chinese & $.61(.54-.69)$ & $.76(.7 I-.83)$ \\
\hline & Filipino & $.47(.4 I-.55)$ & $.69(.62-.76)$ \\
\hline & Hawaiian & $.48(.39-.59)$ & $.67(.58-.76)$ \\
\hline \multirow[t]{5}{*}{$21975-1987$} & Japanese & $.70(.68-.72)$ & $.86(.84-.88)$ \\
\hline & Caucasian & $.74(.72-.77)$ & $.77(.75-.80)$ \\
\hline & Chinese & $.73(.69-.78)$ & $.84(.81-.88)$ \\
\hline & Filipino & $.66(.62-.70)$ & $.77(.74-.81)$ \\
\hline & Hawaiian & $.67(.62-.72)$ & $.83(.80-.87)$ \\
\hline \multirow[t]{5}{*}{$31988-2000$} & Japanese & $.82(.81-.84)$ & $.81(.79-.83)$ \\
\hline & Caucasian & $.82(.80-.84)$ & $.75(.73-.78)$ \\
\hline & Chinese & $.82(.79-.86)$ & $.79(.75-.83)$ \\
\hline & Filipino & $.81(.78-.84)$ & $.76(.72-.80)$ \\
\hline & Hawaiian & $.73(.69-.77)$ & $.79(.75-.83)$ \\
\hline
\end{tabular}

Notes. Probabilities (with $95 \%$ confidence intervals) of surviving five years among three cohorts of colorectal cancer patients by ethnicity and cause of death are provided. Values reflect the estimates controlling for the effects of SEER stage at diagnosis, year of diagnosis, age, and sex. 
Table 4: Determinants for Five-year Survival Among Three Cohorts of Colorectal Cancer Patients.

\begin{tabular}{|c|c|c|c|c|c|c|c|c|c|}
\hline \multirow[t]{2}{*}{ COHORT } & \multirow[t]{2}{*}{ VARIABLE } & \multicolumn{4}{|c|}{ DEATH BY COLORECTAL CANCER } & \multicolumn{4}{|c|}{ DEATH BY OTHER CAUSES } \\
\hline & & $\beta$ & s.e. & $\chi^{2}(1)$ & $e^{\beta}$ & $\beta$ & s.e. & $\chi^{2}(1)$ & $e^{\beta}$ \\
\hline \multirow{4}{*}{$\begin{array}{l}11960- \\
1974\end{array}$} & Stage & 1.28 & .050 & $659.0 *$ & 3.61 & 0.35 & .044 & $65.5^{*}$ & 1.42 \\
\hline & Year & -0.43 & .071 & $36.6^{*}$ & 0.65 & -0.04 & .071 & 0.3 & 0.96 \\
\hline & Age & 0.18 & .025 & $50.4^{*}$ & 1.20 & 0.56 & .025 & $521.2^{*}$ & 1.75 \\
\hline & Sex & -0.08 & .066 & 1.5 & 0.92 & -0.28 & .056 & $25.6 *$ & 0.75 \\
\hline \multirow{4}{*}{$\begin{array}{c}21975- \\
1987\end{array}$} & Stage & 1.66 & .037 & $2029.3^{*}$ & 5.25 & 0.29 & .036 & $68.8^{*}$ & 1.34 \\
\hline & Year & -0.14 & .064 & 4.8 & 0.87 & 0.05 & .061 & 0.7 & 1.05 \\
\hline & Age & 0.16 & .020 & $64.2^{*}$ & 1.17 & 0.70 & .022 & $997.9 *$ & 2.01 \\
\hline & Sex & -0.13 & .047 & 7.4 & 0.88 & -0.35 & .045 & $61.3^{*}$ & 0.71 \\
\hline \multirow{4}{*}{$\begin{array}{c}31988- \\
2000\end{array}$} & Stage & 1.80 & .037 & $2398.7^{*}$ & 6.07 & 0.37 & .036 & $102.1^{*}$ & 1.44 \\
\hline & Year & -0.01 & .052 & 0.1 & 0.99 & 0.37 & .079 & $22.0 *$ & 1.45 \\
\hline & Age & 0.16 & .021 & $58.6^{*}$ & 1.17 & 0.58 & .023 & $616.2^{*}$ & 1.79 \\
\hline & Sex & -0.10 & .048 & 4.7 & 0.90 & -0.29 & .048 & $37.5^{*}$ & 0.75 \\
\hline
\end{tabular}

Notes. Determinants for five-year survival among three cohorts of colorectal cancer patients by cause of death are provided. All values were obtained using the method of partial maximum likelihood estimation in Cox regression. $\beta$ is the regression coefficient, and is equivalent to the log of the hazard ratio. s.e. is the standard error of the regression coefficient and is used for calculating chi-square, which in turn is used for determining the statistical significance of $\beta \cdot \chi^{2}(I)$ is the chi-square value with one degree of freedom (each variable provides a single degree of freedom) and is calculated as $(\beta / \text { s.e. })^{2}$. $e^{\beta}$ is the hazard ratio and is interpreted in the standard fashion. For Year (of diagnosis) and Age, the parameters reflect the estimated change per 10-year increment. Sex is coded with male as the control. An asterisk indicates significance at the .000I level; none of the others was significant within the experimentwise $\alpha$-level set to .005 .

ences. Interestingly, however, Hawaiians did not appear to be receiving less treatment; and with respect to chemotherapy and radiation, appear to have been receiving more than the other ethnic groups. One possible explanation for this is that treatment is causing adverse effects and death. Another is that doctors see prognostic signs of severe disease that are not measured by our covariates, and therefore prescribe more treatment. That is, Hawaiians may have more advanced disease than staging alone indicates.

The implications of these findings are important. If differential screening constitutes the primary reason for ethnic survival disparities, it should be possible to achieve equally favorable outcomes in all ethnic groups. With the exception of the Hawaiians, the evidence presented here reflects a convergence in terms of screening, medical care, and colorectal cancer survival among all ethnic groups. Further efforts are needed to examine why Hawaiians do not follow the overall trend, and how to make improvements. In this regard, a Native Hawaiian cancer network called the Imi Hale is attempting, along with support from the National Cancer Institute, to increase screening for colorectal cancer in Native Hawaiians. [27]
One limitation of this study is that data are restricted to the state of Hawaii. However, even though there are clearly potential regional differences in ethnic patterns of survival, the results of this study could be important beyond Hawaii. For example, in national studies, it has been shown that African-Americans are less likely than others to receive adjuvant chemotherapy.[28] Differential treatment utilization may drive ethnic outcome disparities. The role of individual patient choice and the role of complicating co-morbid conditions in treatment selection probably play some role, and another limitation of our study is not having access to this information. In future studies, however, we hope to elucidate the impact of such factors.

To this end, an important area for future research is detailed analysis of specific treatments received by cancer patients. For example, beginning in 1988 (the start of the third cohort in the present study) colorectal cancer survival has been improved through the use of 5-fluorouracilleucovorin as adjuvant chemotherapy.[29] This factor, as well as improving stage distribution through screening, has undoubtedly contributed to the greatly improved colorectal cancer survival rates in the third cohort. Unfortunately, the HTR does not provide adequate detail with 


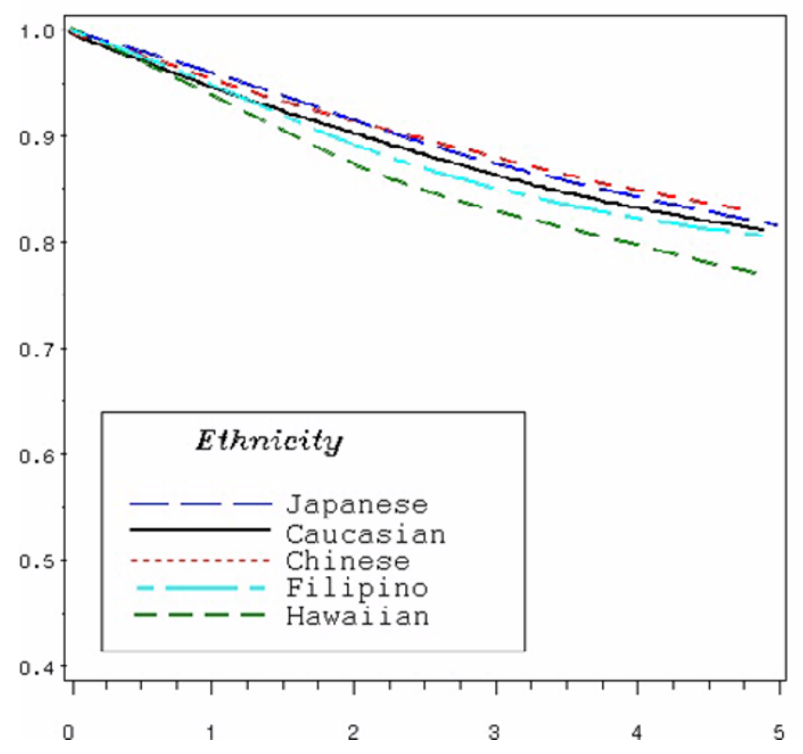

Figure 2

Estimated Survival versus Time (Years) by Ethnicity. Estimated survival (survivor functions) versus survival time (years) stratified by ethnicity for the third cohort (19882000) controlling for the effects of SEER stage at diagnosis, year of diagnosis, age, sex, and treatment are provided. respect to specific chemotherapy treatments, so this hypothesis could not be examined here. However, future studies incorporating expanded data sources should examine whether Hawaiians have been receiving adjuvant 5-FU-leucovorin to the same degree as others, and if not, why not (e.g., access, informed choice with refusal of recommended treatment, or co-morbid disease).

Conversely, if Hawaiians receive apparently similar adjuvant therapy (i.e., same agents, dosage, number of courses, etc.), do they benefit to the same degree as others? Also, do they show a similar degree of treatment compliance? These issues may be of particular relevance, because results from this study suggest that Hawaiians are equally likely, if not more likely, to receive treatments.

Hawaiians have been reported to have relatively high rates of diabetes, renal and vascular disease, and tend to be afflicted at a younger age. Perhaps an interaction between cancer treatment and comorbid conditions is having a negative effect on Hawaiians. We speculate that co-morbid illness might play a role in treatment selection for some individuals with colorectal cancer. Collection of ICD-9 diagnosis codes from non-HRT sources with appropriate record linkage would allow us to study this.

Table 5: Frequencies and Percentages of Treatments by SEER Stage and Ethnic Group for Cohort 3 (1988-2000).

\begin{tabular}{|c|c|c|c|c|c|c|c|c|c|}
\hline \multirow[t]{3}{*}{ STAGE } & \multirow[t]{3}{*}{ ETHNICITY } & \multicolumn{8}{|c|}{ TREATMENT } \\
\hline & & \multicolumn{2}{|c|}{ Surgery } & \multicolumn{2}{|c|}{ Chemo } & \multicolumn{2}{|c|}{ Radiation } & \multicolumn{2}{|c|}{ Hormone } \\
\hline & & $\mathrm{N}$ & $\%$ & $N$ & $\%$ & $\mathrm{~N}$ & $\%$ & $\mathrm{~N}$ & $\%$ \\
\hline \multirow[t]{5}{*}{ Local } & Japanese & 1613 & 96.9 & 98 & 5.9 & 49 & 2.9 & 0 & 0.0 \\
\hline & Caucasian & 947 & 95.5 & 90 & 9.1 & 58 & 5.9 & 4 & 0.4 \\
\hline & Chinese & 293 & 98.3 & 7 & 2.3 & 5 & 1.7 & 0 & 0.0 \\
\hline & Filipino & 425 & 96.6 & 29 & 6.6 & 25 & 5.7 & I & 0.2 \\
\hline & Hawaiian & 290 & 97.3 & 32 & 10.7 & 23 & 7.7 & 1 & 0.3 \\
\hline \multirow[t]{5}{*}{ Regional } & Japanese & 1190 & 98.4 & 581 & 49.2 & 173 & 14.4 & 11 & 0.9 \\
\hline & Caucasian & 685 & 96.3 & 281 & 40.7 & 123 & 17.4 & 3 & 0.4 \\
\hline & Chinese & 188 & 98.4 & 88 & 47.1 & 30 & 15.8 & I & 0.5 \\
\hline & Filipino & 326 & 98.2 & 124 & 37.6 & 56 & 16.9 & 0 & 0.0 \\
\hline & Hawaiian & 265 & 95.0 & 149 & 54.4 & 66 & 23.8 & 3 & I.I \\
\hline \multirow[t]{5}{*}{ Distant } & Japanese & 314 & 69.5 & 240 & 54.3 & 53 & 11.8 & 2 & 0.4 \\
\hline & Caucasian & $25 I$ & 69.9 & 126 & 36.2 & 31 & 8.7 & 4 & I.I \\
\hline & Chinese & 42 & 60.9 & 34 & 50.8 & 10 & 14.5 & 1 & 1.5 \\
\hline & Filipino & 103 & 70.6 & 79 & 55.2 & 21 & 14.5 & 2 & I.4 \\
\hline & Hawaiian & 107 & 70.4 & 86 & 57.7 & 32 & 21.1 & 2 & 1.3 \\
\hline
\end{tabular}


Other results from this study indicate that age at diagnosis is another significant predictor of survival, with older individuals having a shorter life expectancy after diagnosis. However, a comparison of hazard ratios by cause of death showed that the values were much lower for death due to colorectal cancer than for other causes. This suggests that, while age is clearly related to overall survival, it is less relevant to colorectal cancer survival. That is, colon cancer is not more deadly for older individuals than for younger ones. Similarly, sex appears to predict colorectal cancer survival. A small beneficial effect was observed for women when considering death due to colorectal cancer, but a strong effect when considering death due to other causes. The impact of co-morbid disease on survival might explain these age and gender differentials.

Stage at diagnosis represents the most important prognostic variable. In this study the SEER staging system was used so that identical analyses could be performed across all three cohorts. However, for the most recent cohort (cohort 3), TNM staging clearly improved survival predictions over the less comprehensive SEER staging. In future studies, we will use TNM staging whenever possible.

\section{Conclusions}

This study provided longitudinal evidence in support of non-biologic explanations for ethnic disparities in colorectal cancer survival. Specifically, the present analysis suggests that observed ethnic differences result from differential screening. In Hawaii, ethnic disparities in colorectal cancer survival have narrowed considerably over the past 30 years. However, Hawaiian patients did not experience the same degree of improvement in survival as the other ethnic groups.

\section{Competing interests}

None declared.

\section{Authors' contributions}

IP participated in the design of the study, drafted the manuscript, and performed the statistical analyses. SM, SD, $\mathrm{SH}$, and GM participated in the design of the study.

All authors read and approved the final manuscript.

\section{Acknowledgements}

The help of the staff of the Hawaii Tumor Registry is greatly appreciated. This research was supported by a special study grant from the National Cancer Institute, Surveillance, Epidemiology, and End Results program under contract number NOI-PC6700I.

\section{References}

I. Ries LA, Wingo PA, Miller DS, Howe HL, Weir HK, Rosenberg HM, Vernon SW, Cronin K and Edwards BK The annual report to the nation on the status of cancer, 1973-1997, with a special section on colorectal cancer. Cancer 2000, 88:2398-424
2. Howe HL, Wingo PA, Thun MJ, Ries LA, Rosenberg HM, Feigal EG and Edwards BK Annual report to the nation on the status of cancer (1973 through 1998), featuring cancers with recent increasing trends. I Natl Cancer Inst 200I, 93:824-42

3. Piffath TA, Whiteman MK, Flaws JA, Fix AD and Busht TL Ethnic differences in cancer mortality trends in the US, 1950-1992. Ethn Health 200I, 6:105-19

4. Recent trends in mortality rates for four major cancers, by sex and race/ethnicity - United States, 1990-1998. MMWR Morb Mortal Wkly Rep 2002, 5 I:49-53

5. Lin SS, Clarke CA, Prehn AW, Glaser SL, West DW and O'Malley CD Survival differences among Asian subpopulations in the United States after prostate, colorectal, breast, and cervical carcinomas. Cancer 2002, 94: I I75-82

6. Shavers VL and Brown ML Racial and ethnic disparities in the receipt of cancer treatment. J Natl Cancer Inst 2002, 94:334-57

7. Cooper GS, Yuan Z and Rimm AA Racial disparity in the incidence and case-fatality of colorectal cancer: analysis of $\mathbf{3 2 9}$ United States counties. Cancer Epidemiol Biomarkers Prev 1997, 6:283-5

8. Wudel LJ Jr, Chapman WC, Shyr Y, Davidson M, Jeyakumar A, Rogers SO Jr, Allos T and Stain SC Disparate Outcomes in Patients With Colorectal Cancer: Effect of Race on Long-term Survival. Arch Surg 2002, 137:550-6

9. Neuhausen SL Ethnic differences in cancer risk resulting from genetic variation. Cancer 1999, 86:2575-82

10. Roetzheim RG, Pal N, Gonzalez EC, Ferrante JM, Van Durme DJ and Krischer JP Effects of health insurance and race on colorectal cancer treatments and outcomes. Am J Public Health 2000, 90:1746-54

11. Cooper GS, Yuan Z, Landefeld CS and Rimm AA Surgery for colorectal cancer: Race-related differences in rates and survival among Medicare beneficiaries. Am J Public Health 1996, 86:582-6

12. Wojcik BE, Spinks MK and Optenberg SA Breast carcinoma survival analysis for African American and white women in an equal-access health care system. Cancer 1998, 82:1310-8

13. Schrijvers CT, Coebergh JW and Mackenbach JP Socioeconomic status and comorbidity among newly diagnosed cancer patients. Cancer 1997, 80:1482-8

14. Marcella S and Miller JE Racial differences in colorectal cancer mortality. The importance of stage and socioeconomic status. I Clin Epidemiol 200I, 54:359-66

15. Nomura A, Hirohata T, Rellahan W, Burch T, Harris D and Batten G Survivorship from large bowel cancer among Caucasians and Japanese in Hawaii. Cancer 1978, 4I:157I-6

16. Hirohata T, Nomura A, Rellahan W, Burch T, Harris D and Batten G Survival patterns from large bowel cancer in Hawaii. Hawaii Med J 1977, 36:343-7

17. Wegner EL, Kolonel LN, Nomura AM and Lee J Racial and socioeconomic status differences in survival of colorectal cancer patients in Hawaii. Cancer 1982, 49:2208-16

18. Hinds MW, Nomura AM, Kolonel LN and Lee J A comparison of cancer survival by time period of diagnosis in Hawaii, 19601974. Cancer 1983, 5 I: 175-8

19. Maskarinec $G$ and Meng $L$ Trends in cancer survival among different ethnic groups. Cancer Strategy 1999, I: I75- 182

20. Maskarinec G, Pagano IS, Yamashiro G and Issell BF Influences of ethnicity, treatment, and comorbidity on breast cancer survival in Hawaii. Journal of Clinical Epidemiology 2002,

21. Hawaii Department of Business State of Hawaii data book 1997: A statistical abstract. Honolulu: State of Hawaii 1998,

22. Goodman MT, Yoshizawa CN and Kolonel LN Descriptive epidemiology of thyroid cancer in Hawaii. Cancer 1988, 61:1272-81

23. National Cancer Institute SEER Program Code Manual. 1988,

24. Sas Institute SAS/STAT User's Guide, Version 8. Cary, NC: SAS Institute Inc. 1999,

25. Allison PD Survival Analysis Using the SAS System: A Practical Guide. Cary, NC: SAS Institute 1995,

26. National Cancer Institute SEER Extent of Disease Codes and Coding Instructions 1998,

27. Chong $C$ Imi Hale, the Native Hawaiian Cancer Research and Training Network. National Cancer Institute 2000,

28. Potosky AL, Harlan LC, Kaplan RS, Johnson KA and Lynch CF Age, sex, and racial differences in the use of standard adjuvant therapy for colorectal cancer. J Clin Oncol 2002, 20: I 192-202 
29. O'Connell MJ, Mailliard JA, Kahn MJ, Macdonald JS, Haller DG, Mayer $\mathrm{RJ}$ and Wieand HS Controlled trial of fluorouracil and low-dose leucovorin given for 6 months as postoperative adjuvant therapy for colon cancer. J Clin Oncol 1997, I5:246-50

\section{Pre-publication history}

The pre-publication history for this paper can be accessed here:

http://www.biomedcentral.com/1471-2407/3/5/prepub

Publish with Bio Med Central and every scientist can read your work free of charge

"BioMed Central will be the most significant development for disseminating the results of biomedical research in our lifetime. " Sir Paul Nurse, Cancer Research UK

Your research papers will be:

- available free of charge to the entire biomedical community

- peer reviewed and published immediately upon acceptance

- cited in PubMed and archived on PubMed Central

- yours - you keep the copyright

Submit your manuscript here:

http://www.biomedcentral.com/info/publishing_adv.asp 